\title{
Neural and endocranial anatomy of Triassic phytosaurian reptiles and convergence with fossil and modern crocodylians
}

\author{
Stephan Lautenschlager ${ }^{\text {Corresp., }}{ }^{1}$, Richard Butler ${ }^{2}$ \\ ${ }^{1}$ School of Earth Sciences, University of Bristol, Bristol, United Kingdom \\ 2 School of Geography, Earth and Environmental Sciences, University of Birmingham, Birmingham, United Kingdom \\ Corresponding Author: Stephan Lautenschlager \\ Email address: glzsl@bristol.ac.uk
}

Phytosaurs are a clade of large, carnivorous pseudosuchian archosaurs from the Late Triassic with a near cosmopolitan distribution. Their superficial resemblance to longirostrine (long-snouted) crocodylians, such as gharials, has often been used in the past to infer ecological and behavioural convergence between the two groups. Although more than thirty species of phytosaur are currently recognised, little is known about the endocranial anatomy of this clade. Here, we describe the endocranial anatomy (including the brain, inner ear, neurovascular structures and sinus systems) of the two nonmystriosuchine phytosaurs Parasuchus angustifrons (="Paleorhinus angustifrons") and Ebrachosuchus neukami from the Late Triassic of Germany based on digital reconstructions. Results show that the endocasts of both taxa are very similar to each other in their rostrocaudally elongate morphology, with long olfactory tracts, weakly demarcated cerebral regions and dorsoventrally short endosseous labyrinths. In addition, several sinuses, including large antorbital sinuses and prominent dural venous sinuses, were reconstructed. Comparisons with the endocranial anatomy of derived phytosaurs indicate that Phytosauria is united by the presence of elongate olfactory tracts and longitudinally arranged brain architecture - characters which are also shared with Crocodyliformes. However, a substantial morphological variability is observed in the cephalic and pontine flexure and the presence of a pineal organ across the different phytosaur species. These results suggest that the endocranial anatomy in Phytosauria generally follows a plesiomorphic pattern, with moderate variation within the clade likely resulting from divergent sensory and behavioural adaptations. 
1 Neural and endocranial anatomy of Triassic phytosaurian reptiles and convergence with

2 fossil and modern crocodylians

3

4 Stephan Lautenschlager ${ }^{1 *}$, Richard J. Butler ${ }^{2}$

5

$6{ }^{1}$ School of Earth Sciences, University of Bristol, Life Sciences Building, Bristol BS8 1TQ, UK

$7 \quad{ }^{2}$ School of Geography, Earth and Environmental Sciences, University of Birmingham,

8 Birmingham B15 2TT, UK

9

10 *Corresponding author: Stephan Lautenschlager, glzsl@,bristol.ac.uk, +44 (0) 1173315239

11

12 Short title: Neuroanatomy of Phytosauria

13 


\section{ABSTRACT}

Phytosaurs are a clade of large, carnivorous pseudosuchian archosaurs from the Late Triassic with a near cosmopolitan distribution. Their superficial resemblance to longirostrine (longsnouted) crocodylians, such as gharials, has often been used in the past to infer ecological and behavioural convergence between the two groups. Although more than thirty species of phytosaur are currently recognised, little is known about the endocranial anatomy of this clade. Here, we describe the endocranial anatomy (including the brain, inner ear, neurovascular structures and sinus systems) of the two non-mystriosuchine phytosaurs Parasuchus angustifrons (="Paleorhinus angustifrons") and Ebrachosuchus neukami from the Late Triassic of Germany based on digital reconstructions. Results show that the endocasts of both taxa are very similar to each other in their rostrocaudally elongate morphology, with long olfactory tracts, weakly demarcated cerebral regions and dorsoventrally short endosseous labyrinths. In addition, several sinuses, including large antorbital sinuses and prominent dural venous sinuses, were reconstructed. Comparisons with the endocranial anatomy of derived phytosaurs indicate that Phytosauria is united by the presence of elongate olfactory tracts and longitudinally arranged brain architecture - characters which are also shared with Crocodyliformes. However, a substantial morphological variability is observed in the cephalic and pontine flexure and the presence of a pineal organ across the different phytosaur species. These results suggest that the endocranial anatomy in Phytosauria generally follows a plesiomorphic pattern, with moderate variation within the clade likely resulting from divergent sensory and behavioural adaptations. 


\section{INTRODUCTION}

Phytosaurs are a group of fossil archosauriform reptiles commonly found in Upper Triassic (c. 235-202 Ma) sediments in North America and Europe, and less commonly in other regions such as India, Africa, East Asia, Madagascar and South America (Stocker and Butler, 2013). Phytosaurs have usually been regarded as the earliest diverging group within the crocodylian stem-lineage Pseudosuchia (Sereno, 1991; Parrish, 1993; Brusatte et al., 2010; Ezcurra 2016), which together with Avemetatarsalia (pterosaurs, dinosaurs, birds) form the clade Archosauria. One recent phylogenetic dataset has recovered Phytosauria as a monophyletic clade just outside of and as a sister taxon to Archosauria (Nesbitt, 2011), although this result has not been supported by a recent comprehensive revision of the phylogeny of early archosauriforms (Ezcurra, 2016). Morphologically, phytosaurs resemble extant crocodylians, particularly longirostrine morphotypes such as gharials. Members of both groups possess large elongate skulls equipped with conical teeth, rows of sculptured osteoderms covering the axial and appendicular skeleton, and are characterised by a quadrupedal, sprawling gate (Westphal, 1976). Evidence from taphonomy and ichnofossils suggests that, similar to crocodylians, phytosaurs were generally aquatic or semi-aquatic (Buffetaut, 1993; Renesto and Lombardo, 1999), but were also capable of terrestrial locomotion (Parrish, 1986). Although phytosaurs and the earliest fossil crocodylians are significantly separated temporally (by about 100 million years) and phylogenetically, gross morphological similarities between the two groups have often been cited as evidence for ecological and behavioural convergence (Camp, 1930; Anderson, 1936; Hunt, 1989; Hungerbühler, 2002; Witzmann et al., 2014). However, phytosaurs are defined by a number of osteological characters that differentiate them from crocodylians, such as an elongate premaxilla, the caudal position of the external nares (which is placed close to the orbit in 
59 phytosaurs, rather than at the tip of the rostrum), and the absence of a secondary palate.

60 Convergence in the form of a longirostrine skull shape has occurred numerous times throughout

61 the evolution of pseudosuchian archosaurs (Brochu, 2001); presumably as an adaptation to a

62 specific habitat and diet (e.g. piscivory) (Pierce et al., 2008). However, the extent to which this

63

64

65

66

67

68 osteological convergence is also reflected in soft-tissue structures, such as the endocranial anatomy, remains unclear. Neuroanatomical adaptations to a specific ecology or behaviour in phylogenetically divergent groups as drivers for morphological similarities have been suggested in avemetatarsalian ("bird-line") archosaurs (Witmer et al., 2003).

In the past, research on phytosaurs has largely focussed on comparative osteology, taxonomy and phylogenetic relationships. Due to their near-global geographic distribution but restricted temporal distribution phytosaurs have been used as index fossils in biostratigraphy. In comparison, the reconstruction and study of the endocranial anatomy of phytosaurs has received little attention (e. g. Cope, 1888; Case, 1928; Mehl, 1928; Camp, 1930; Chatterjee, 1978). Most recently, Holloway et al. (2013) described a digital endocast of the derived mystriosuchine phytosaur Machaeroprosopus mccauleyi (="Pseudopalatus mccauleyi") in order to evaluate the evolution of sensory systems in archosaurs.

Here, we describe the endocranial anatomy (including the brain, inner ear, neurovascular structures and sinus systems) of the two non-mystriosuchine phytosaurs Parasuchus angustifrons (=“Paleorhinus angustifrons") and Ebrachosuchus neukami (Butler et al., 2014; see Kammerer et al. 2016 for recent taxonomic revisions) (Fig. 1) based on digital reconstructions. Further comparisons are made with existing reconstructions for other phytosaurian and crocodylian taxa. 


\section{Specimens}

83 The studied specimens consist of the holotypes of Ebrachosuchus neukami (BSPG 1931 X 501;

84 Bayerische Staatssammlung für Paläontologie und Geologie, Munich, Germany) and Parasuchus

85 angustifrons (BSPG 1931 X 502) (Kuhn 1936; Butler et al., 2014). The skull of Ebrachosuchus

86 neukami is fully articulated and complete and preparation work has removed most of the

87 sandstone matrix, with the exception of most internal cavities, which remain filled with matrix.

88 The skull of Parasuchus angustifrons is articulated and mostly complete apart from the

89 premaxilla, of which only a small portion immediately rostral to the external nares is preserved.

90 Sandstone matrix remains within most of the internal cavities. Both of the skulls have undergone

91 some plastic deformation, primarily in the form of dorsoventral compression, but are otherwise

92 remarkably well preserved, with minimum transverse distortion. Brittle deformation and

93 fracturing are largely absent.

94

\section{CT scanning and digital reconstruction}

The holotypes of Ebrachosuchus neukami (BSPG 1931 X 501) and Parasuchus angustifrons (BSPG 1931 X 502) were scanned at the Klinikum rechts der Isar (Munich) using a Siemens SOMATOM Sensation 64 CT scanner. Datasets consisted of 1634 slices $(512$ x 512 x 1634 pixels, $0.6 \mathrm{~mm}$ voxel size) for Ebrachosuchus neukami and 809 slices (512 x 512 x 1634 pixels, $0.6 \mathrm{~mm}$ voxel size) for Parasuchus angustifrons. CT data sets are deposited with the specimens in the BSPG collections and on Fgshare.(https://figshare.com/). endosseous labyrinths, neurovascular and sinus structures) were labelled using Avizo’s 
105

106

107

108

109

110

111

112

113

114

115

116

117

118

119

120

121

122

123

124

125

126

127

segmentation editor. The magic wand tool was used where possible to perform the segmentation semi-automatically. In regions with poor contrast between matrix, bone and structures of interest the paintbrush tool was used for manual segmentation. 3D surface models and volumes were created to visualize the segmented structures and to illustrate this article with traditional figures. In addition, surface models of the individual structures were downsampled to a degree that allowed for small file sizes but preserved all details, and were exported as separate OBJ files for the creation of the interactive 3D figures in the supplementary material as outlined in Lautenschlager (2014) using Adobe 3D reviewer (Adobe Systems Inc.).

As both taxa have been compressed dorsoventrally to a moderate amount, the resulting endocasts were retrodeformed. For the retrodeformation process, the digital skull and endocast models were scaled in dorsoventral direction using the "transform editor" in Avizo. BSPG 1931 X 502 was scaled to the same dorsoventral dimensions as a less compressed skull of Parasuchus hislopi (ISI R42, Indian Statistical Institute, Kolkata, India), corresponding to a scaling factor of approximately 40\%. The same scaling factor was assumed for BSPG 1931 X 501 based on the fact that both specimens were found in close proximity to one another on a single bedding plane and likely had a similar diagenetic history (Butler et al., 2014).

\section{Anatomical abbreviations}

airw, airway; antorb, antorbital sinus; c, cochlear duct; car, carotid artery; cer, cerebral hemisphere; crc, crus communis; csc, caudal semicircular canal; cvcm, caudal middle cerebral vein; dsl, diverticulum of longitudinal sinus; dur, dural venous sinus; ecto, ectotympanic sinus;

fl, floccular lobe; fv, fenestra vestibuli; lab, endosseous labyrinth; lsc, lateral semicircular canal; nvc, neurovascular canal; ob, olfactory bulbs; ot, olfactory tracts; pit, pituitary fossa; pmx, 
128 premaxillary sinus; rsc, rostral semicircular canal; $\mathbf{I V}$, trochlear nerve canal; $\mathbf{V}_{\mathbf{1}}$, ophthalmic

129 branch of the trigeminal nerve canal; $\mathbf{V}_{\mathbf{2}}$, maxillary branch of the trigeminal nerve canal; $\mathbf{V}_{\mathbf{3}}$,

130 mandibular branch of the trigeminal nerve canal; VI, abducens nerve canal; VII, facial nerve

131 canal; IX-XI, shared canal for the glossopharyngeal, vagus and spinal accessory nerve; XII,

132 hypoglossal nerve canal.

134 RESULTS

\section{Endocranial anatomy}

137

138

139

140

141

142

The endocasts of Ebrachosuchus neukami and Parasuchus angustifrons are very similar in their morphology. Both endocasts are elongate, straight (i.e. arranged horizontally) and mediolaterally narrow (Figs. 2, 3). Long olfactory tracts extend rostrally and are as long as the main portion of the endocasts in each taxon. Fossae for olfactory bulbs are preserved in both taxa, but only in Parasuchus angustifrons is a rostral separation into two olfactory bulbs visible (Fig. 2B). The ventral extent could not be reconstructed as no bony structures cover this region. The cerebrum and the cerebral hemispheres are only weakly demarcated and form the widest part of the endocast in each taxon. Again, in Parasuchus angustifrons the cerebral hemispheres are slightly more prominent than in Ebrachosuchus neukami. The mid- and hindbrain region, including the cerebellum, is mediolaterally compressed between the endosseous labyrinths in both taxa.

Caudally, the endocasts increase in width towards the foramen magnum. The floccular lobes, extending from the cerebellum, are prominent but short. In comparison to the more oval-shaped morphology in Parasuchus angustifrons, the floccular lobes are slightly dorsoventrally flattened in Ebrachosuchus neukami (Fig. 3A). In both taxa, the floccular lobes enter the vestibular 
151 apparatus of the endosseous labyrinth, but do not extend beyond the rostral semicircular canal.

152 Despite the elongate morphology of the endocasts, the cephalic flexure (between the fore- and

153 mid-brain) and the pontine flexure (between the mid- and hindbrain) are pronounced in the

154 endocasts. The cast of the pituitary fossa is prominent and extends ventrally from the ventral

155 surface of the cerebrum. The pituitary fossae have equal dimensions and positions in both taxa.

156 The canals of the neurovascular structures were reconstructed for as far as indicated by

157 osteological correlates. Their arrangement and dimensions are similar in Ebrachosuchus neukami

158 and Parasuchus angustifrons. The optic nerve (CN II) and the oculomotor nerve (CN III) canals

159 could not be traced due to the lack of preserved bony structures on the rostroventral part of the

160 endocasts. The trochlear nerve canal (CN IV) is small and originates from the ventral surface of

161 the cerebrum, rostral to the trigeminal nerve $(\mathrm{CN} \mathrm{V})$. The latter is prominent in both taxa and

162 originates from the ventrolateral surface of the midbrain region. A split into a rostrally directed

163 ophthalmic branch $\left(\mathrm{CN} \mathrm{V}_{1}\right)$ and a laterally projecting combined canal for the maxillary $\left(\mathrm{CN} \mathrm{V}_{2}\right)$

164 and mandibular $\left(\mathrm{CN} \mathrm{V}_{3}\right)$ branches is evident in both endocasts. A subdivision of the latter two is

165 not visible in the CT scans, but most likely occurred further outside of the endocranial cavity as

166 is the plesiomorphic archosaurian condition (Witmer et al., 2008). The canal for the abducens

167 nerve (CN VI) originated from the ventral surface of the endocast below the trigeminal nerve

168 canal. The canal for the facial nerve (CN VII) is situated caudal to that of the abducens nerve.

169 The vestibulocochlear nerve canal (CN VIII) could not be reconstructed in either taxon as the

170 resolution of the CT scans is not clear enough in this region to identify the nerve canal

171 confidently. A large metotic fissure is present in both taxa, transmitting the glossopharyngal (CN

172 IX), the vagus (CN X) and the spinal accessory nerves (CN XI). The hypoglossal nerve (CN XII)

173 exits the braincase via a single nerve canal. A further foramen located dorsal to the hypoglossal 
174 nerve foramen has a blind ending and likely represents a diverticulum of the longitudinal sinus 175 (Witmer and Ridgely, 2008, 2009).

Due to the resolution of the CT data set only the larger vascular structures could be

177

178

179

180

reconstructed. The roots of the caudal middle cerebral vein are prominent and originate from the cerebellum rostrodorsally to the floccular lobes in Ebrachosuchus neukami and Parasuchus angustifrons. They can be traced caudally through the bone for a short extent exiting the braincase near the supraoccipital-parietal suture. Ventrally, the canals for the carotid artery originate from the pituitary fossa and exit the basisphenoid ventrolaterally.

In comparison to the other endocranial components, the endosseous labyrinths of Ebrachosuchus neukami and Parasuchus angustifrons show more prominent differences (Fig. 6). In general, the labyrinths are dorsoventrally short and compact. The vestibular apparatus approaches a rectangular outline and is rostrocaudally elongate in both taxa, but more pronounced in Ebrachosuchus neukami. This may partly due to the preservation of Parasuchus angustifrons, which seems to have been dorsoventrally compacted to a moderate extent (Fig. 6A, B). In Ebrachosuchus neukami, the rostral semicircular canal is the longest and describes a somewhat quadrangular shape, whereas the caudal semicircular canal is more oval-shaped (Fig. 6C, D). The lateral semicircular canal is short and compact. The semicircular canals in Parasuchus angustifrons appear, as far as preserved, dorsoventrally compressed and with more uniform dimension than in Ebrachosuchus neukami, although this is partly a preservational artefact. The cochlear ducts are short in Ebrachosuchus neukami and Parasuchus angustifrons and extend largely ventrally, with only a slight medial component. The fenestra vestibuli were reconstructed in Ebrachosuchus neukami and Parasuchus angustifrons.

As with the endocranial cavities, the arrangement and extent of the various sinuses is 
197 similar in Ebrachosuchus neukami and Parasuchus angustifrons (Fig. 4, 5). The antorbital sinus

198 is large and fills the antorbital fenestra, as well as the space between the palate and the palatal

199 shelf of the maxilla. A small diverticulum also appears to enter the jugal via a foramen near the

200 ectopterygoid-jugal contact (Butler et al., 2014) in both taxa. Rostrally, a large canal is present,

201 which opens into the antorbital cavity. The canal likely transmitted neurovascular structures,

202 including the maxillary branch of the trigeminal nerve. The region rostral to the external nares

203 comprises a large air-filled space for the entire length of the premaxilla medial to the

204 neurovascular canal supplying the alveolar cavities. This region may have housed a premaxillary

205 sinus (most likely as extension of the antorbital sinus) and/or neurovascular bundles (Butler et

206 al., 2014) as in extant crocodiles (Leitch and Catania, 2012). The airway is simple and

207 unbranched in Ebrachosuchus neukami and Parasuchus angustifrons and connects the external

208 nares with the choanae and the olfactory region.

209 In Parasuchus angustifrons, the ectopterygoid is pierced medially by a single oval

210 foramen opening into a large cavity within the bone (Fig. 4). No further foramina are

211 identifiable, suggesting the foramen connected to a pneumatic recess rather than transmitting

212 neurovascular structures. The pneumatic recess is either part of the antorbital sinus or a separate

213 ectopterygoid sinus of unknown source (Witmer, 1997). The respective region is only partly

214 preserved and damaged, but a similarly large cavity appears to be absent in Ebrachosuchus

215 neukami. A further sinus located dorsal to the brain endocast is present in Ebrachosuchus

216 neukami and Parasuchus angustifrons. While this structure could be interpreted as part of the

217 paratympanic sinus, there is no clear connection to the middle ear visible in the datasets. In both

218 taxa, it covers the cerebellum dorsally. In Ebrachosuchus neukami two small diverticula extend

219 rostrally covering the cerebrum dorsolaterally. These diverticula are not visible in Parasuchus 
220

221

222

223

224

225

226

227

228

229

230

231

232

233

234

235

236

237

238

239

240

241

242

angustifrons. Laterally, subsidiary canals of the tympanic sinus are present in both taxa, but more pronounced in Parasuchus angustifrons, in which they exit the braincase via a foramen between

the parietal and the prootic and connect to the caudal tympanic recess. This sinus possibly had a further connection to the quadrate foramen, but the pathway for this canal is not indicated by osteological correlates. The sinus is therefore most likely a combination of the endocranium and the dural venous sinuses.

\section{Comparison with other phytosaurs}

A comparison with other phytosaurs shows that, while similar to each other, the endocranial anatomy of Ebrachosuchus neukami and Parasuchus angustifrons differs in several aspects from that of more derived taxa (Fig. 7). However, it should be noted that accurate comparisons are exacerbated by the scarcity of detailed reconstructions of endocasts. Existing reconstructions are mostly based on physical casts (natural and artificial) or interpretive drawings (Cope, 1888;

Case, 1928; Mehl, 1928; Camp, 1930; Chatterjee, 1978). All phytosaur endocasts appear to share a basic bauplan with the individual brain regions arranged longitudinally (in contrast to a more vertical arrangement such as seen in birds) and a mediolaterally narrow morphology. The olfactory tracts are significantly elongate in all taxa (as far as preserved/reconstructed), making up approximately half the length of the entire endocasts. Caudal to the olfactory tracts, the various taxa show large differences in the orientation of the individual brain portions. Cephalic and pontine flexure is very variable. While Ebrachosuchus neukami and Parasuchus angustifrons share very large flexure angles (following Lautenschlager and Hübner, 2013) with derived taxa, such as Machaeroprosopus pristinus and Machaeroprosopus buceros, the fore- and mid-brain and the mid- and hind-brain appear to be almost perpendicular to each other in 
243 Smilosuchus gregori and Parasuchus hislopi. However, although the studied specimens of

244 Parasuchus angustifrons (BSPG 1931 X 502) and Ebrachosuchus neukami (BSPG 1931 X 501)

245 are well preserved and mostly complete, they show signs of moderate dorsoventral compaction.

246 Retrodeformed endocast reconstructions exhibit cephalic and pontine flexures more similar to

247 Machaeroprosopus mccauleyi and Parasuchus hislopi. A significant difference is found in the

248 presence of a pineal organ or epiphysis dorsal to the cerebrum. A pineal organ has been

249 suggested to be present (Jaekel, 1910; Langston, 1949) and been reconstructed for the majority

250 of phytosaurs, but is absent in Ebrachosuchus neukami and Parasuchus angustifrons. The dorsal

251 expansion in the respective region in these taxa is interpreted in this study to represent parts of

252 the dural venous sinus or alternatively the paratympanic sinus, due to the rostral and lateral

253 expansion of this structure into parts of the braincase. Hopson (1979) similarly considered a

254 pineal organ in phytosaurs unlikely and suggested that the respective region in the endocranial

255 cavity housed a cartilaginous portion of the supraoccipital. Although reconstructed by Mehl

256 (1928), an enlarged epiphysis was reported to be absent in Machaeroprosopus pristinus in an as-

257 yet-unpublished recent study (Smith et al., 2010). Existing endocast reconstructions provide

258 ambiguous results regarding the presence of the epiphysis, but suggest that it may have

259 elaborated through phytosaur evolution (Fig. 7). However, considering its absence in modern

260 crocodilians, the epiphysis must have been lost at some stage prior to the origin of the

261 crocodilian crown group.

262 Similar to the actual brain endocast, the endosseous labyrinths show, as far as

263 reconstructed, subtle differences between different phytosaurian taxa. The vestibular part of the

264 labyrinth of Ebrachosuchus neukami and Parasuchus angustifrons is rostrocaudally longer than

265 dorsoventrally high, whereas it seems to have more uniform dimensions in Machaeroprosopus 
266 mccauleyi and Leptosuchus sp. Again, this is to some extent a result of dorsoventral

267 compression. The retrodeformed endosseous labyrinths of Ebrachosuchus neukami and

268 Parasuchus angustifrons are more similar to the labyrinth of Leptosuchus sp. It should be noted,

269 though, that the retrodeformation is based on dorsoventral scaling of the complete skull and

270 endocast, respectively. However, the opisthotic and the paroccipital, which house the endosseous

271 labyrinth, might not have suffered the same amount of compression as the complete skull.

272 Furthermore, the scarcity of reconstructed and preserved natural labyrinthine endocasts

273 confounds wider comparisons.

274

275 Comparison with Crocodyliformes

276 As in comparison with other phytosaurs, the endocranial anatomy of Ebrachosuchus

277 neukami and Parasuchus angustifrons shares a basic bauplan with most Crocodyliformes in the

278 form of a longitudinally arranged and elongate brain architecture thought to be plesiomorphic for

279 the whole lineage (Hopson, 1979). As in phytosaurs, the olfactory tracts are elongate in extant

280 crocodylians, including Alligator mississippiensis (Witmer and Ridgely, 2008), Crocodylus

281 johnstoni (Witmer et al., 2008) and Crocodylus moreleti (Franzosa, 2004), as well as in several

282 phylogenetically distinct Mesozoic longirostrine crocodylomorphs, such as the neosuchian

283 Pholidosaurus (Edinger, 1938; Hopson, 1979) and the metriorhynchid Cricosaurus araucanensis

284 (Herrera et al., 2013). In contrast to phytosaurs, the cerebral hemispheres are prominent and

285 mediolaterally enlarged in most Crocodyliformes (Wharton, 2000; Franzosa, 2004; George and

286 Holliday, 2013). Extant crocodylians possess an enlarged dural venous sinus covering the

287 endocast dorsally (Witmer et al., 2008), which has been interpreted to be present in fossil

288 Mesoeucrocodylia (Hopson, 1979; Wharton, 2000). Where preserved or reconstructed, the 
289 endosseous labyrinths show a dorsoventrally compressed vestibular region and short cochlear

290 ducts in Crocodyliformes (Franzosa, 2004; Witmer et al., 2008), similar to Ebrachosuchus

291 neukami and Parasuchus angustifrons.

292 Paranasal sinuses have been reconstructed only for a handful of extant and extinct

293 Crocodyliformes (e.g. Alligator mississippiensis, Cricosaurus araucanensis), which limits

294 comparisons of these structures. A clear difference is found in the size of the antorbital sinus. In

295 Ebrachosuchus neukami and Parasuchus angustifrons the antorbital sinus is enlarged, but it is

296 considerably smaller in Crocodyliformes (Witmer and Ridgely, 2008; Herrera et al., 2013). Due

297 to the position of the external nares the airway is short in the studied phytosaurs. In the

298 longirostrine metriorhynchid Cricosaurus araucanensis, the rostrum comprises the airway for its

299 entire length (Herrera et al., 2013), whereas the comparable region was likely filled by a

300 premaxillary sinus in phytosaurs.

301

302

\section{DISCUSSION}

The reconstruction of the endocranial anatomy of Ebrachosuchus neukami and

304

305

306

307

308

309

310

311
Parasuchus angustifrons suggests that the general bauplan of pseudosuchian brain architecture

was already established in Phytosauria. Plesiomorphic characters, such as elongate olfactory

tracts, a mediolaterally narrow and serially aligned brain and a comparably small cerebral region, are largely retained in other phytosaurs, but also in most Crocodyliformes. In contrast, features that occur in the evolution of avemetatarsalian archosaurs such as a rearrangement of the brain architecture, a hyperinflated cerebrum and a reduction of the olfactory apparatus (Zelenitsky et al., 2011; Balanoff et al., 2013) are absent in the pseudosuchian lineage.

However, in spite of these overall similarities there are a number of differences present in 
312 the endocranial anatomy when comparisons are made between various phytosaurian taxa, but

313 also in comparison to the (admittedly small number of) available endocranial reconstructions of

314 Crocodyliformes. Whether these reflect subtle ecological or behavioural adaptations,

315 intraspecific variation or interpretive artefacts is difficult to discern. The small sample size and

316 lack of detailed, three-dimensional reconstructions currently prevents rigorous tests of the latter

317 two possibilities. It is generally assumed that the osteological similarities between phytosaurs

318 and longirostrine Crocodyliformes are the result of convergent evolution and the adaptation to

319 the same habitat and/or diet (e.g. Camp, 1930; Hunt, 1989). Similarities or differences in the

320 endocranial anatomy could therefore indicate adaptive changes of key structures. Apart from the

321 plesiomorphic morphology of the brain inherent to both phytosaurs and Crocodyliformes, both

322 groups share a dorsoventrally flattened and rostrocaudally expanded morphology of the

323 vestibular apparatus of the inner ear. Such an increase in the aspect ratio of the vertical

324 semicircular canals has been associated with an adaptation to an aquatic environment (Georgi

325 and Sipla, 2008) and is found also in other marine reptiles (Neenan and Scheyer, 2012). It

326 therefore possible that the endocranial anatomy in phytosaurs and longirostrine Crocodyliformes

327 follows a shared plesiomorphic pattern that has been convergently modified in response to

328 similar sensory adaptations. Additional sampling of phytosaur and fossil crocodyliform

329 endocasts and more refined palaeobehavioural and palaeoecological data will be required to 330 provide a more definitive assessment of this hypothesis.

\section{CONCLUSIONS}

The digital reconstruction of the brain, inner ear, neurovascular and sinus morphology of

334 the two non-mystriosuchine phytosaurs Parasuchus angustifrons and Ebrachosuchus neukami 
335 offers new insights into the endocranial anatomy and evolution of Phytosauria. The endocasts of

336 both taxa are very similar to each other in their rostrocaudally elongate morphology, with long

337 olfactory tracts, weakly demarcated cerebral regions and dorsoventrally short endosseous

338 labyrinths. Several sinuses, including large antorbital sinuses and prominent dural venous

339 sinuses, were reconstructed. Comparisons with published endocranial reconstructions of other,

340 more derived, phytosaurian taxa demonstrate a substantial morphological variability, most

341 pronounced in the cephalic and pontine flexure and the presence of a pineal organ. Endocranial

342 characters that are found across all phytosaurs, as far as preserved, include the elongate olfactory

343 tract and a serially arranged brain architecture. As far as allowed by the limited available

344 comparative data, these features appear to be shared with members of the clade Crocodyliformes.

345 However, the scarcity of reconstructed endocasts for phytosaurs and crocodyliforms, as well as

346 preservational artefacts, confound large-scale comparisons and provide an impetus for further

347 future work on the endocranial anatomy and evolution of these clades.

348

349 ACKNOWLEDGEMENTS

350 We thank Martin Dobritz (Klinikum rechts der Isar, Munich) for CT scanning and Oliver Rauhut

351 (BSPG, Munich) for access to specimens. We thank Jon Tennant (Imperial College London) and

352 Ryan Ridgely (Ohio University) for their helpful reviews of an earlier version of this manuscript.

353

354

LITERATURE CITED

355

Anderson HT. 1936. The jaw musculature of the phytosaur Machaeroprosopus. Journal of

356 Morphology 59:549-587. 
357 Balanoff AM, Bever GS, Rowe TB, and Norell MA. 2013. Evolutionary origins of the avian $358 \quad$ brain. Nature 501:93-96.

359 Brochu CA. 2001. Crocodylian snouts in space and time: phylogenetic approaches toward 360 adaptive radiation. . American Zoologist 41:564-585.

361

362

363

364

365

366

367

368

369

370

371

372

373

374

375

376

377

378

Brusatte SL, Benton MJ, Desojo JB, and Langer MC. 2010. The higher-level phylogeny of Archosauria (Tetrapoda: Diapsida). Journal of Systematic Palaeontology 8:3-47.

Buffetaut E. 1993. Phytosaurs in time and space. In: Mazin JM, and Pinna G, eds. Evolution, Ecology and Biogeography of the Triassic Reptiles. Milan: Paleontologia Lombarda della Societa Italiana di Scienze Naturali e del Museo Civico di Storia Naturale, 39-44.

Butler RJ, Rauhut OWM, Stocker MR, and Bronowicz R. 2014. Redescription of the phytosaurs Paleorhinus ('Francosuchus') angustifrons and Ebrachosuchus neukami from Germany, with implications for Late Triassic biochronology. Zoological Journal of the Linnean Society 170:155-208.

Camp CL. 1930. A study of the phytosaurs with description of new material from western North America. Memoirs of the University of California 10:1-174.

Case EC. 1928. An endocranial cast of a phytosaur from the Upper Triassic beds of western Texas. Journal of Comparative Neurology 45:161-168.

Chatterjee S. 1978. A primitive parasuchid (Phytosaur) reptile from the Upper Triassic Maleri Formation of India. Palaeontology 21:83-127.

Cope ED. 1888. The pineal eye in extinct vertebrates. The American Naturalist 22:914-917.

Edinger T. 1938. Über Steinkerne von Hirn- und Ohr-Höhlen der Mesosuchier Goniopholis und Pholidosaurus aus dem Bückeburger Wealden. Acta Zoologica 19:467-505. 
379 Ezcurra MD. 2016. The phylogenetic relationships of basal archosauromorphs, with an emphasis 380 on the systematics of proterosuchian archosauriforms. PeerJ 4:e1778. 10.7717/peerj.1778

381 Franzosa JW. 2004. Evolution of the brain in Theropoda (Dinosauria) Unpublished PhD thesis.

$382 \quad$ University of Texas.

383 George ID, and Holliday CM. 2013. Trigeminal nerve morphology in Alligator mississippiensis and its significance for crocodyliform facial sensation and evolution. Anat Rec 296:670680.

Georgi JA, and Sipla JS. 2008. Comparative and functional anatomy of balance in aquatic reptiles and birds. In: Thewissen JGM, and Nummela S, eds. Sensory Evolution on the Threshold: Adaptations in Secondarily Aquatic Vertebrates. Berkeley, California.: University of California Press, 233-256.

Herrera Y, Fernandez MS, and Gasparini Z. 2013. The snout of Cricosaurus araucanensis: a case study in novel anatomy of the nasal region of metriorhynchids. Lethaia 46:331-340.

Holloway WL, Claeson KM, and O'Keefe FR. 2013. A virtual phytosaur endocast and its implications for sensory system evolution in archosaurs. Journal of Vertebrate Paleontology 33:848-857.

Hopson JA. 1979. Paleoneurology. In: Gans C, Northcutt RC, and Ulinski P, eds. Biology of the Reptilia. New York: Academic Press, 39-146.

Hungerbühler A. 2002. The Late Triassic phytosaur Mystriosuchus westphali, with a revision of the genus. Palaeontology 45:377-418.

Hunt AP. 1989. Cranial morphology and ecology among phytosaurs. In: Lucas SG, and Hunt AP, eds. Dawn of the Age of Dinosaurs in the American Southwest. Albuquerque: New Mexico Museum of Natural History, 349-354. 
402 Jaekel O. 1910. Ueber einen neuen Belodonten aus dem Buntsandstein von Bernberg. 403 Sitzungsberichte Gesellschaft naturforschender Freunde zu Berlin 5:197-229.

404 Kammerer CF, Butler RJ, Bandyopadhyay S, and Stocker MR. 2016. Relationships of the Indian 405 phytosaur Parasuchus hislopi Lydekker, 1885. Papers in Palaeontology 2:1-23.

406 Kuhn O. 1936. Weitere Parasuchier und Labyrinthodonten aus dem Blasensandstein des

407 mittleren Keuper von Ebrach. Palaeontographica Abteilung A 83: 61-98.

408 Langston WL, Jr. 1949. A new species of Paleorhinus from the Triassic of Texas. American $409 \quad$ Journal of Science 247:324-341.

410 Lautenschlager S. 2014. Palaeontology in the third dimension: a comprehensive guide for the integration of three-dimensional content in publications. Paläontologische Zeitschrift $88: 111-121$.

Lautenschlager S, and Hübner T. 2013. Ontogenetic trajectories in the ornithischian endocranium. Journal of Evolutionary Biology 26:2044-2050.

Leitch DB, and Catania KC. 2012. Structure, innervation and response properties of integumentary sensory organs in crocodilians. Journal of Experimental Biology 215:4217-4230.

Mehl MG. 1928. Pseudopalatus pristinus, a new genus and species of phytosaurs from Arizona. University of Missouri Studies 3:1-22.

Neenan JM, and Scheyer TM. 2012. The braincase and inner ear of Placodus gigas (Sauropterygia, Placodontia) — a new reconstruction based on micro-computed tomographic data. Journal of Vertebrate Paleontology 32:1350-1357.

Nesbitt SJ. 2011. The early evolution of archosaurs: relationships and the origin of major clades. Bulletin of the American Museum of Natural History 352:1-292. 
425 Parrish JM. 1986. Structure and function of the tarsus in the phytosaurs (Reptilia: Archosauria).

426 In: Padian K, ed. The beginning of the Age of Dinosaurs: Faunal Change Across the

427 Triassic-Jurassic Boundary. Cambridge: Cambridge University Press, 35-43.

428 Parrish JM. 1993. Phylogeny of the Crocodylotarsi, with reference to archosaurian and crurotarsan monophyly. Journal of Vertebrate Paleontology 13:287-308.

430

431

432

433

434

435

436

437

438

439

440

441

442

443

444 445

446

447

Pierce SE, Angielczyk KD, and Rayfield EJ. 2008. Patterns of morphospace occupation and mechanical performance in extant crocodilian skulls: a combined geometric morphometric and finite element modeling approach. Journal of Morphology 269:840864.

Renesto S, and Lombardo C. 1999. Structure of the tail of a phytosaur (Reptilia, Archosauria) from the Norian (Late Triassic) of Lombardy (northern Italy). Rivista Italiana di Paleontologia e Stratigrafia 105:135-144.

Sereno PC. 1991. Basal archosaurs: phylogenetic relationships and functional implications. Society of Vertebrate Paleontology Memoir 2:1-53.

Smith D, Sanders R, Parker W, and Cavanaugh J. 2010. The endocranium, inner ear, and pneumatic structure of the Upper Triassic phytosaur Pseudopalatus pristinus. Journal of Vertebrate Paleontology, SVP Program and Abstracts Book:176A.

Stocker MR, and Butler RJ. 2013. Phytosauria. Geological Society, London, Special Publications 379:91-117.

Westphal F. 1976. Phytosauria. In: O K, ed. Handbuch der Paläoherpetologie. Stuttgart: Gustav Fischer Verlag, 99-120.

Wharton DS. 2000. An enlarged endocranial venous system in Steneosaurus pictaviensis (Crocodylia: Thalattosuchia) from the Upper Jurassic of Les Lourdines, France. Comptes 

226.

450

451

452

453

454

455

456

457

458

459

460

461

462

463

464

465

466

467

468

469
Encyclopedia of Dinosaurs. New York: Academic Press, 151-159.

Witmer LM, Chatterjee S, Franzosa JW, and Rowe T. 2003. Neuroanatomy of flying reptiles and implications for flight, posture and behaviour. Nature 425:950-953.

Witmer LM, and Ridgely RC. 2008. The paranasal air sinuses of predatory and armored dinosaurs (Archosauria: Theropoda and Ankylosauria) and their contribution to cephalic structure. The Anatomical Record 291:1362-1388.

Witmer LM, and Ridgely RC. 2009. New insights into the brain, braincase, and ear region of tyrannosaurs (Dinosauria, Theropoda), with implications for sensory organization and behavior. The Anatomical Record 292:1266-1296.

Witmer LM, Ridgely RC, Dufeau DL, and Semones MC. 2008. Using CT to peer into the past: 3D visualization of the brain and ear regions of birds, crocodiles, and nonavian dinosaurs. In: Endo H, and Frey R, eds. Anatomical Imaging - Towards a new morphology. Tokyo, Berlin, Heidelberg, New York: Springer, 67-87.

Witzmann F, Schwarz-Wings D, Hampe O, Fritsch G, and Asbach P. 2014. Evidence of spondyloarthropathy in the spine of a phytosaur (Reptilia: Archosauriformes) from the Late Triassic of Halberstadt, Germany. PLOS ONE 9:e85511.

Zelenitsky DK, Therrien F, Ridgely RC, McGee AR, and Witmer LM. 2011. Evolution of olfaction in non-avian theropod dinosaurs and birds. Proceedings of the Royal Society London, Series B 278:3625-3634. 


\section{FIGURE CAPTIONS}

472 Figure 1 Studied phytosaurian taxa. Physical specimen (left) and digital representation (right)

473 of (A) Parasuchus angustifrons (BSPG 1931 X 502) and (B) Ebrachosuchus neukami (BSPG

4741931 X 501).

475

476

Figure 2 Endocranial anatomy of Parasuchus angustifrons (BSPG 1931 X 502). Endocast of brain and endosseous labyrinth in (A) left lateral and (B) dorsal view. Endocast in situ in (C) left lateral and (D) dorsal view with bone rendered semi-transparent.

479

480

Figure 3. Endocranial anatomy of Ebrachosuchus neukami (BSPG 1931 X 501). Endocast of brain and endosseous labyrinth in (A) left lateral and (B) dorsal view. Endocast in situ in (C) left 482 lateral and (D) dorsal view with bone rendered semi-transparent.

483

484

Figure 4 Paranasal sinuses of Parasuchus angustifrons (BSPG 1931 X 502). Sinuses in (A) 485 and $(\mathbf{B})$ in rostrolateral view and $(\mathbf{C})$ and (D) dorsal view. Sinuses in (B) and (D) in situ with 486 bone rendered semi-transparent.

487

Figure 5 Paranasal sinuses of Ebrachosuchus neukami (BSPG 1931 X 501). Sinuses in (A)

489 and (B) in rostrolateral view and (C) and (D) dorsal view. Sinuses in (B) and (D) in situ with 490 bone rendered semi-transparent. 
492 Figure 6 Endosseous labyrinths. Parasuchus angustifrons (BSPG 1931 X 502) (A) left

493 labyrinth, (B) right labyrinth. Ebrachosuchus neukami (BSPG 1931 X 501) (C) left labyrinth, (D)

494 right labyrinth. Each from left to right in lateral, caudal, rostral, medial and dorsal view. Parts

495 reconstructed and reflected from the opposite side (where preserved) shown in different colour.

Figure 7 Endocranial anatomy of different phytosaurian taxa. Comparisons based on

498

499

500

501

502

503

504

505

506

existing endocasts and endocast reconstruction redrawn from Cope (1888), Case (1928), Mehl (1928), Camp (1930), Chatterjee (1978) and Holloway et al. (2013). Time-calibrated phylogeny based on Stocker and Butler (2013), Kammerer et al. (2016) and Ezcurra (2016). Endocasts of Parasuchus angustifrons and Ebrachosuchus neukami shown after retrodeformation.

Figure 8 Retrodeformation of studied taxa. (A) Complete and undistorted skull of Parasuchus hislopi (ISI R42) used as a guide for retrodeformation of (B) Parasuchus angustifrons (BSPG 1931 X 502) and (C) Ebrachosuchus neukami (BSPG 1931 X 501). Original (top) and retrodeformed (bottom) skull and respective endocasts shown for each taxon. 
Figure 1

Studied phytosaurian taxa.

Physical specimen (left) and digital representation (right) of (A) Parasuchus angustifrons (BSPG 1931 X 502) and (B) Ebrachosuchus neukami (BSPG 1931 X 501).

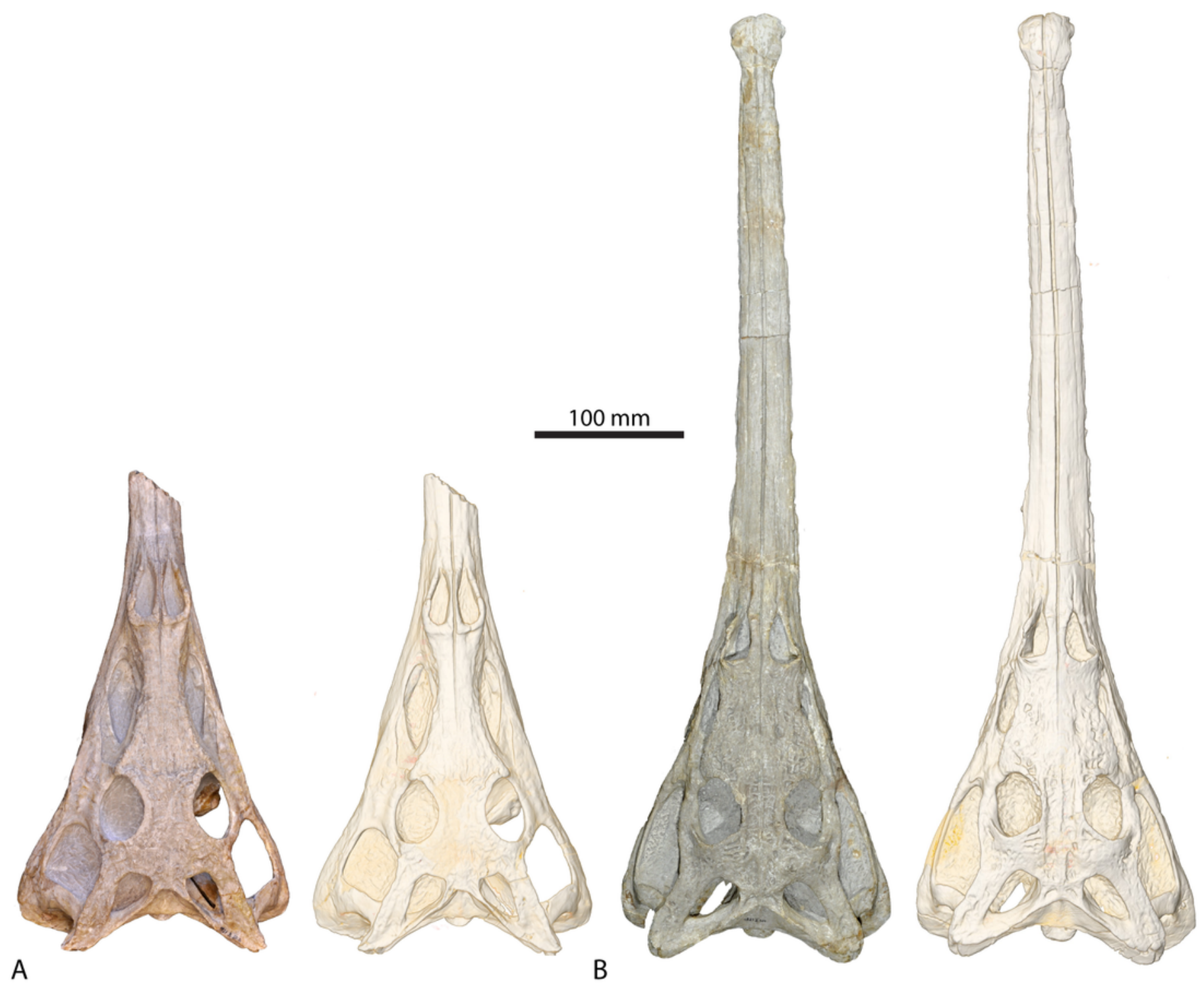


Figure 2

Endocranial anatomy of Parasuchus angustifrons (BSPG 1931 X 502).

Endocast of brain and endosseous labyrinth in (A) left lateral and (B) dorsal view. Endocast in situ in (C) left lateral and (D) dorsal view with bone rendered semi-transparent. 
A

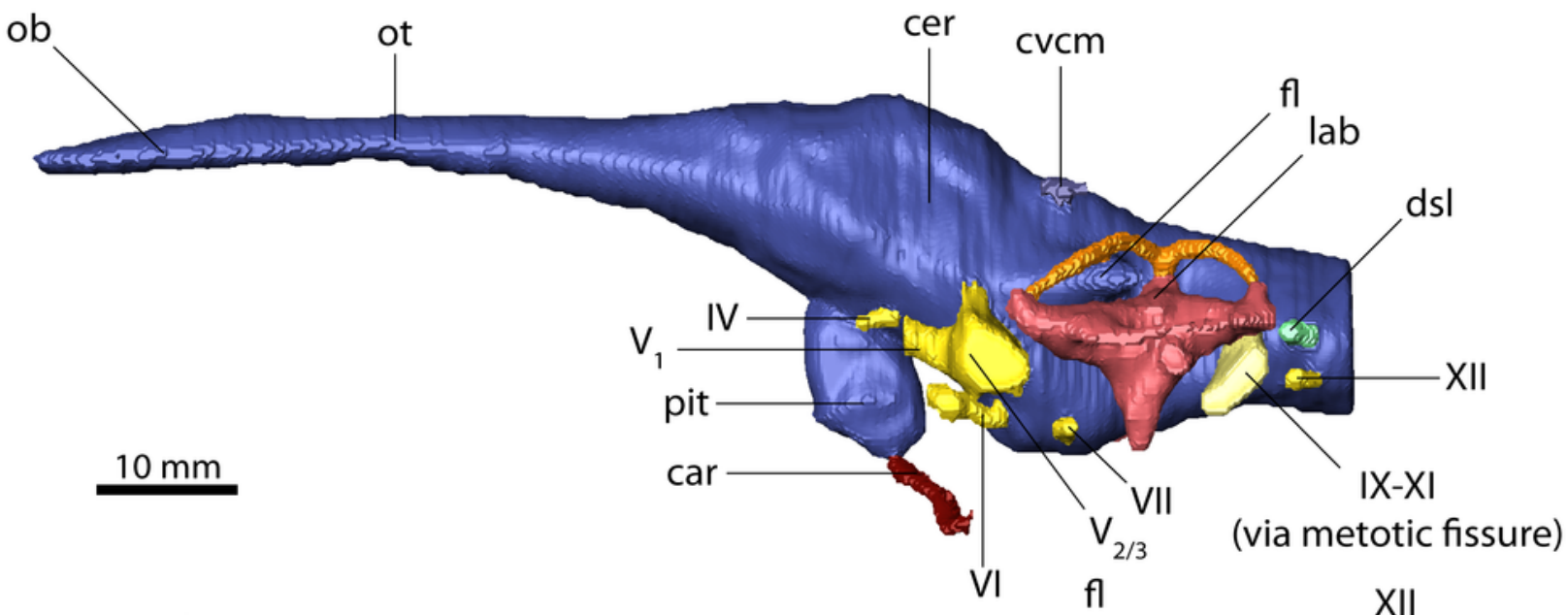

B
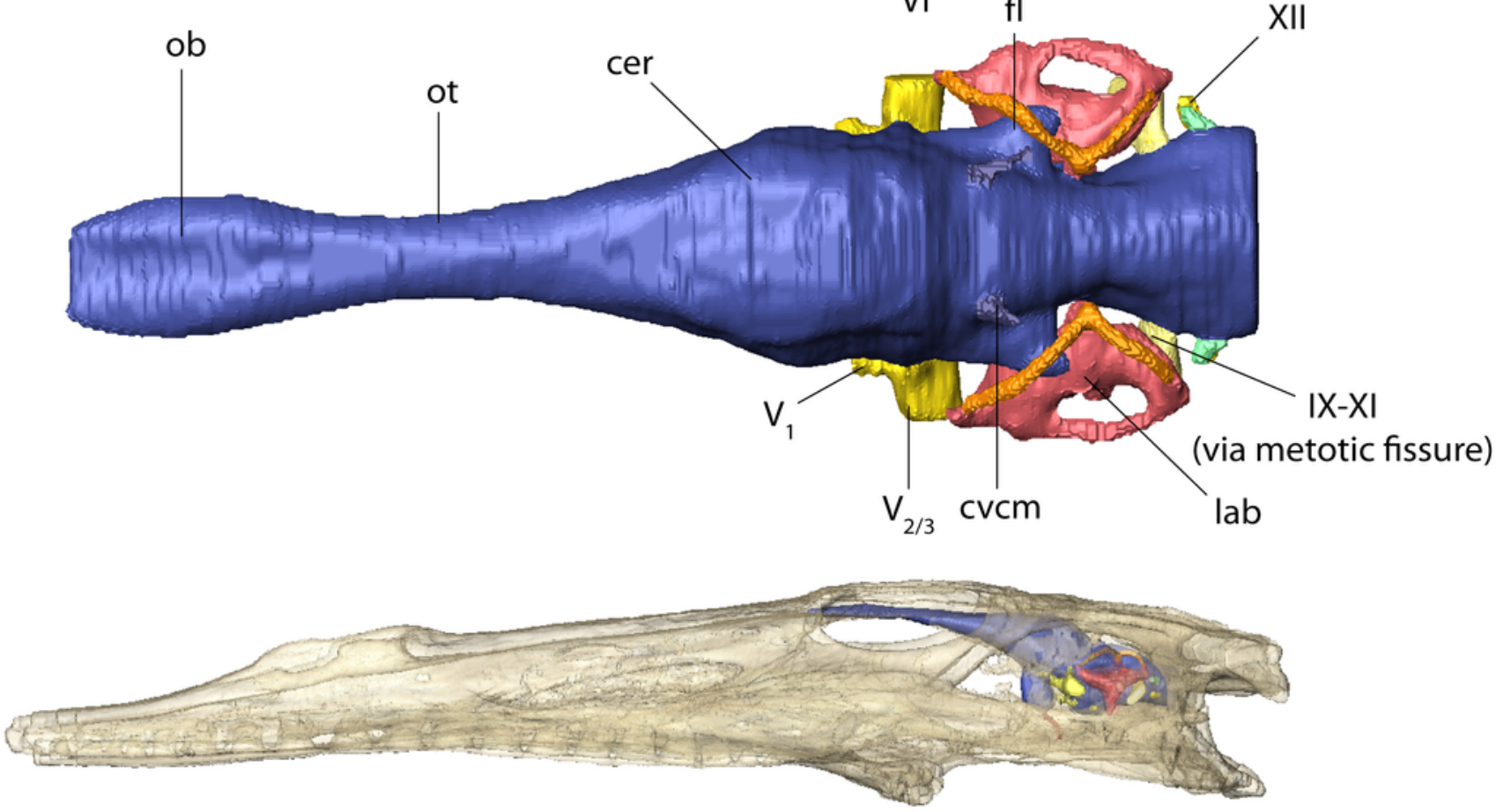

C

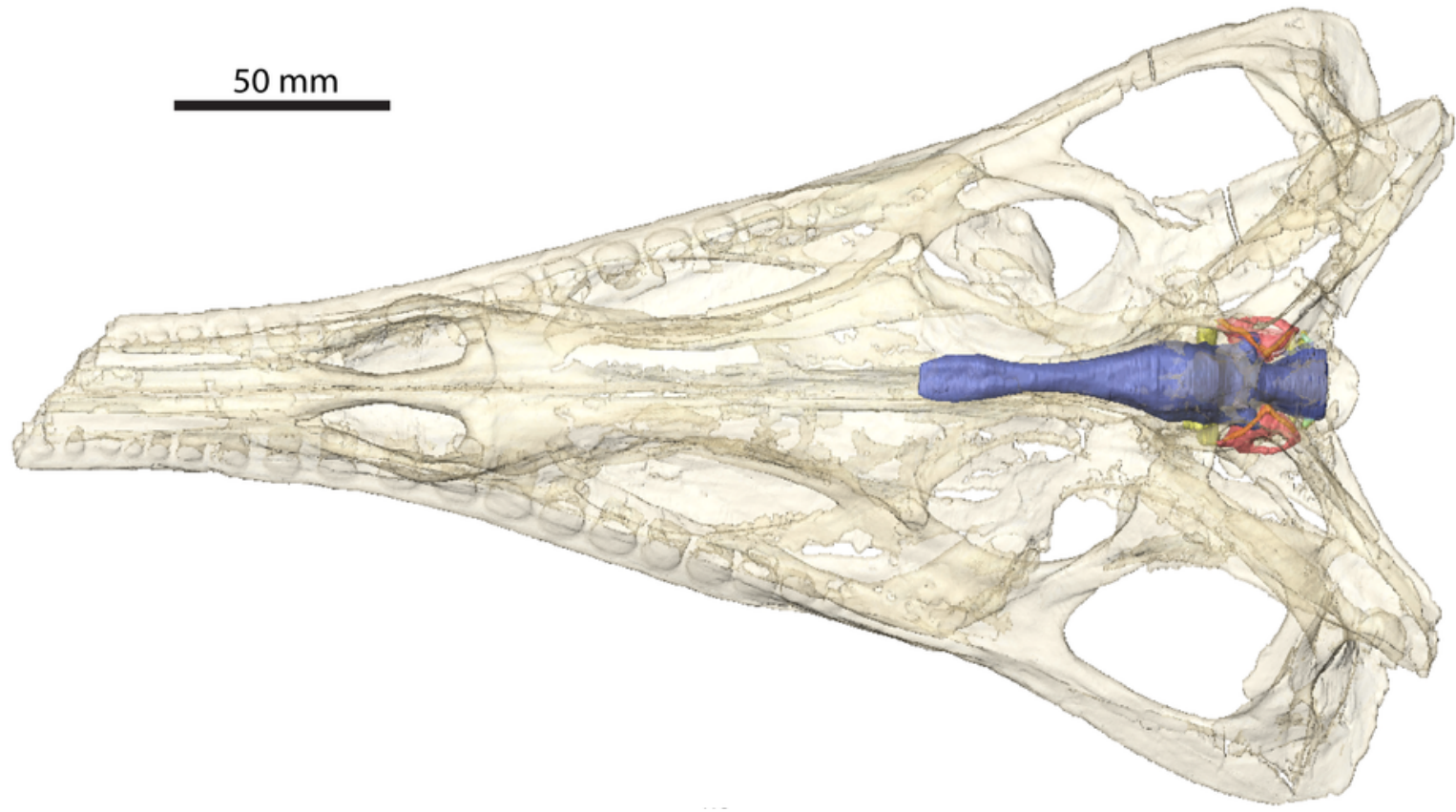




\section{Figure 3}

Endocranial anatomy of Ebrachosuchus neukami (BSPG 1931 X 501).

Endocast of brain and endosseous labyrinth in (A) left lateral and (B) dorsal view. Endocast in situ in (C) left lateral and (D) dorsal view with bone rendered semi-transparent. 


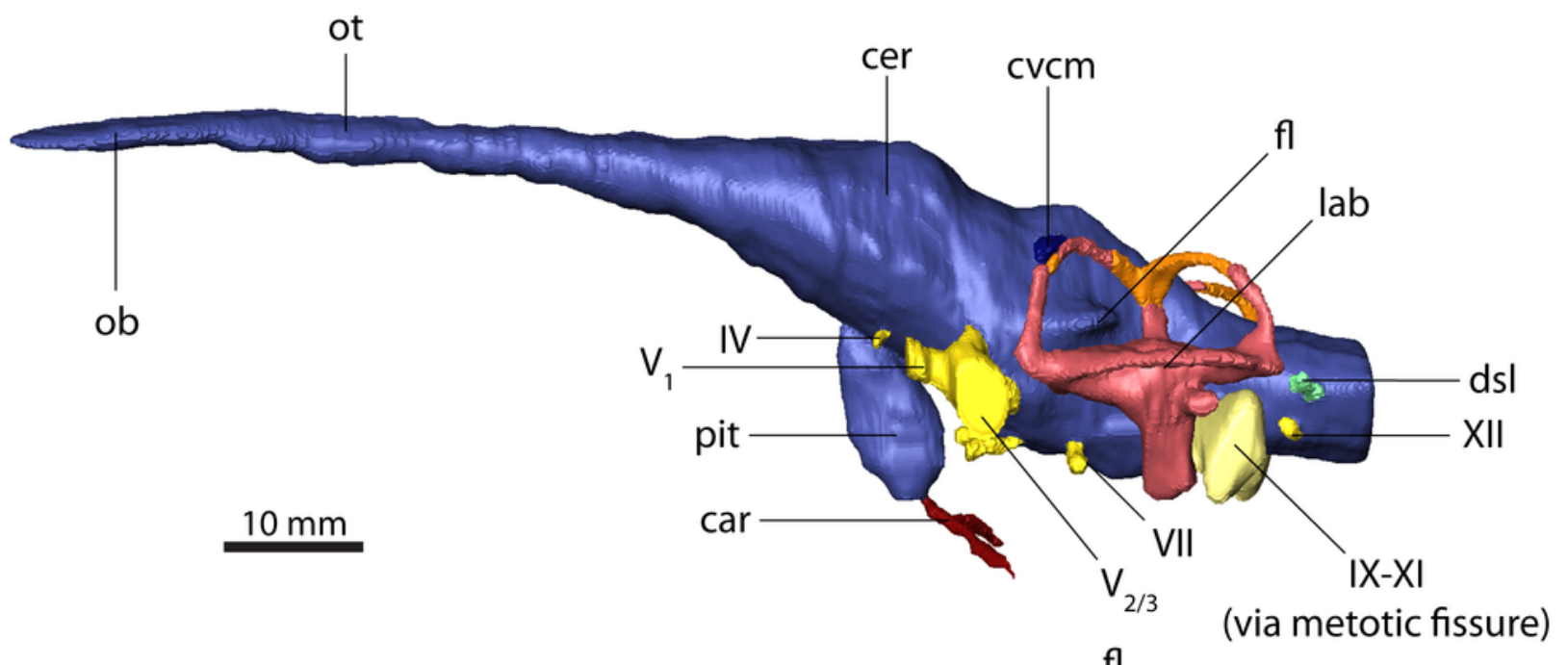

A

B

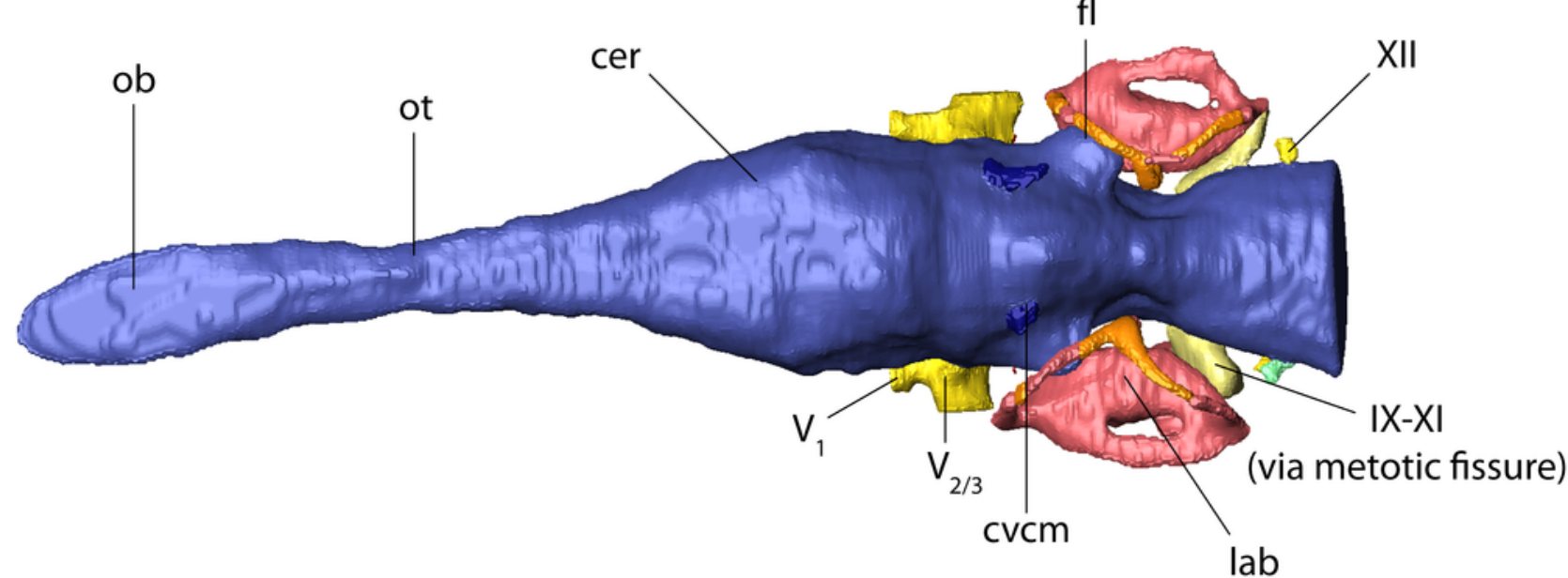

C $\quad 50 \mathrm{~mm}$

D 


\section{Figure 4}

Paranasal sinuses of Parasuchus angustifrons (BSPG 1931 X 502).

Sinuses in (A) and (B) in rostrolateral view and (C) and (D) dorsal view. Sinuses in (B) and (D) in situ with bone rendered semi-transparent. 


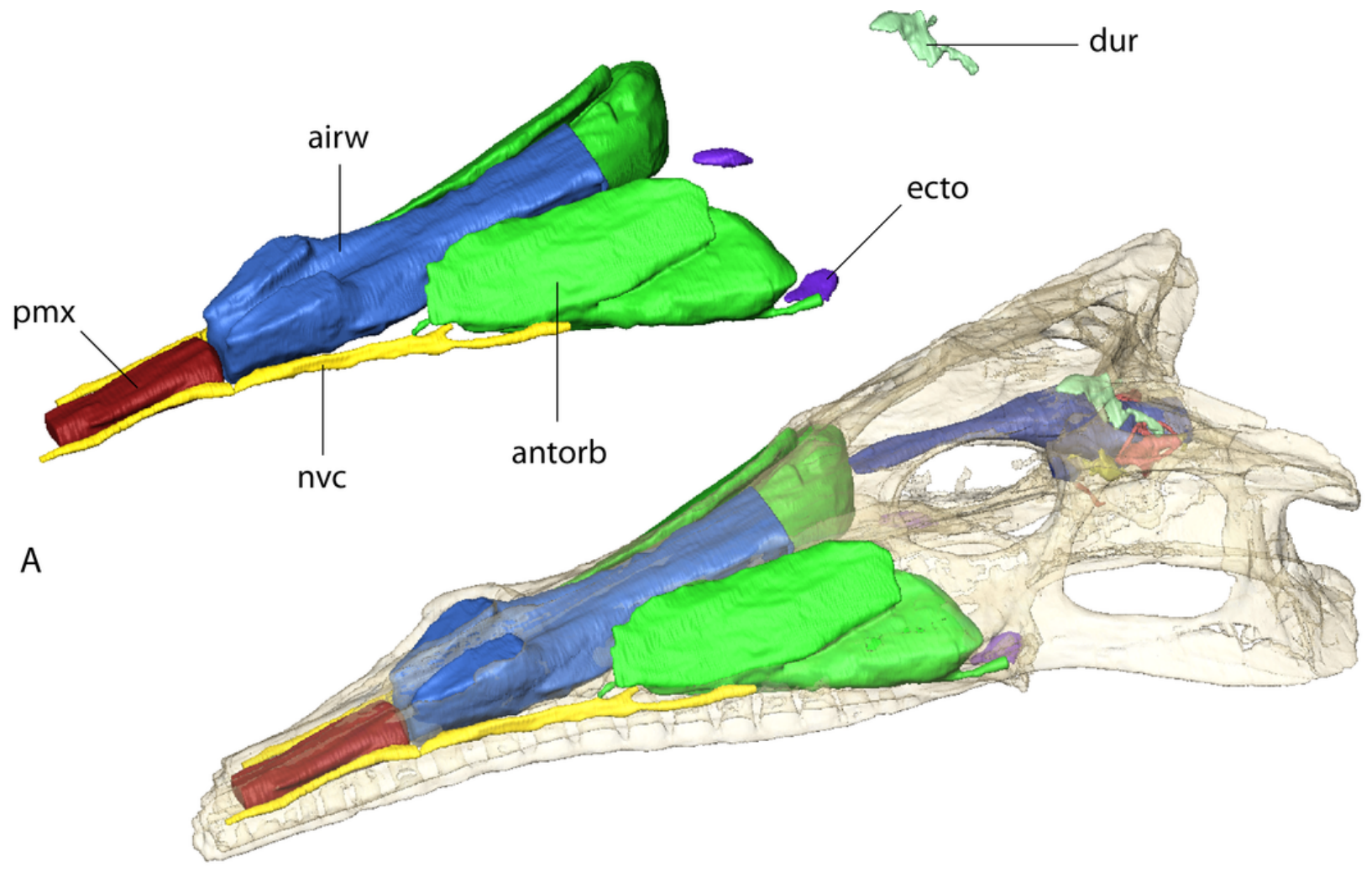

B

C

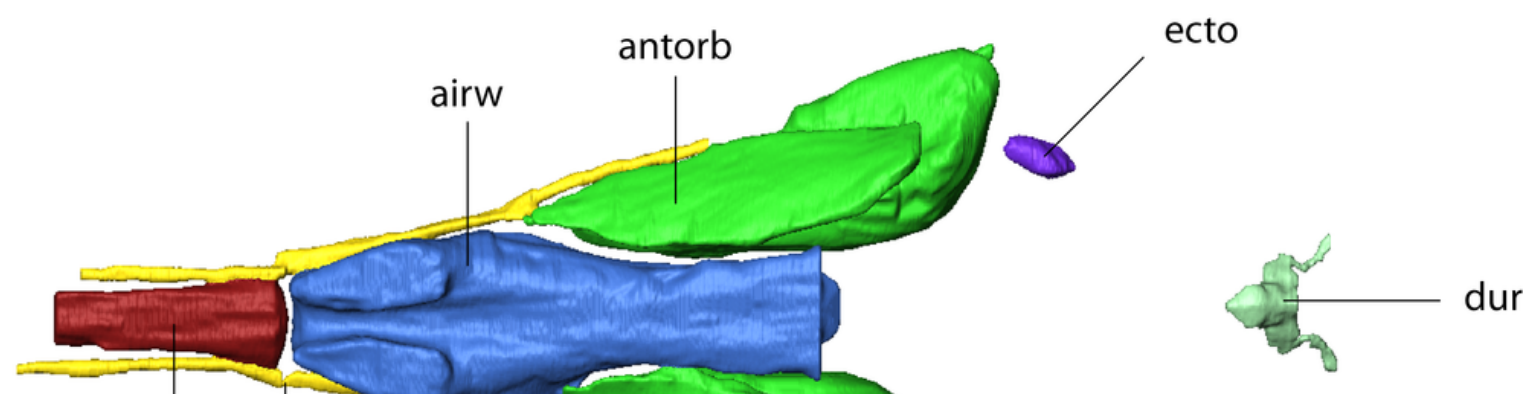

D $50 \mathrm{~mm}$ 
Figure 5

Paranasal sinuses of Ebrachosuchus neukami (BSPG 1931 X 501).

Sinuses in (A) and (B) in rostrolateral view and (C) and (D) dorsal view. Sinuses in (B) and (D) in situ with bone rendered semi-transparent.
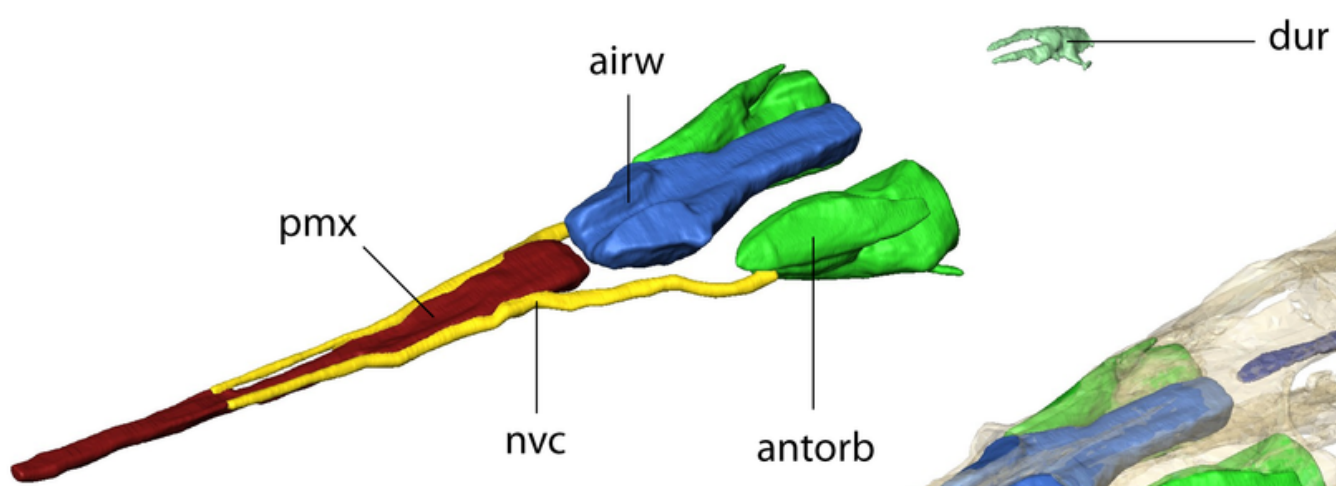

A

B

C
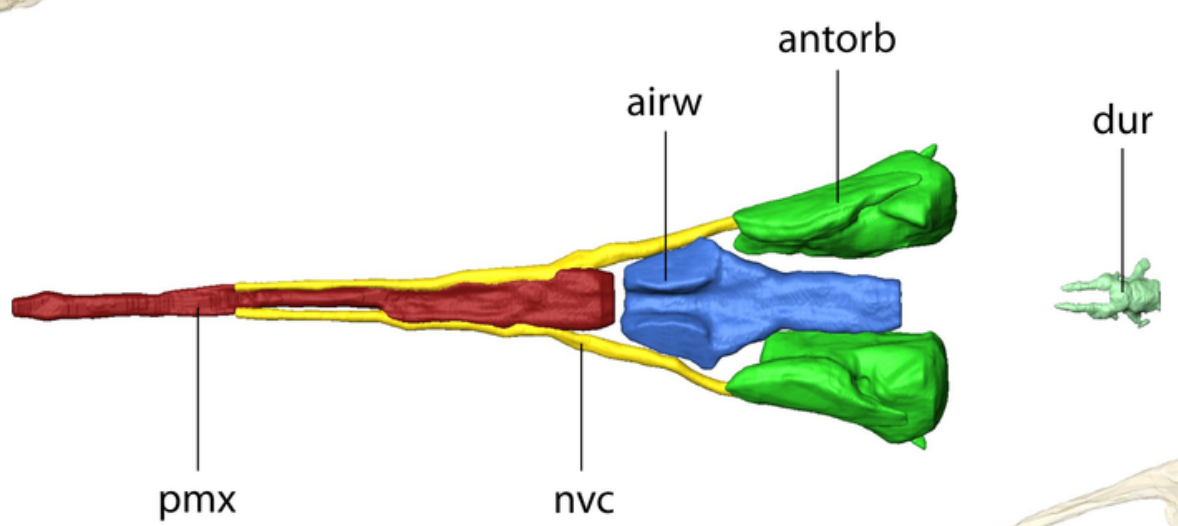

D 


\section{Figure 6}

Endosseous labyrinths.

Parasuchus angustifrons (BSPG 1931 X 502) (A) left labyrinth, (B) right labyrinth.

Ebrachosuchus neukami (BSPG 1931 X 501) (C) left labyrinth, (D) right labyrinth. Each from left to right in lateral, caudal, rostral, medial and dorsal view. Parts reconstructed and reflected from the opposite side (where preserved) shown in different colour. 

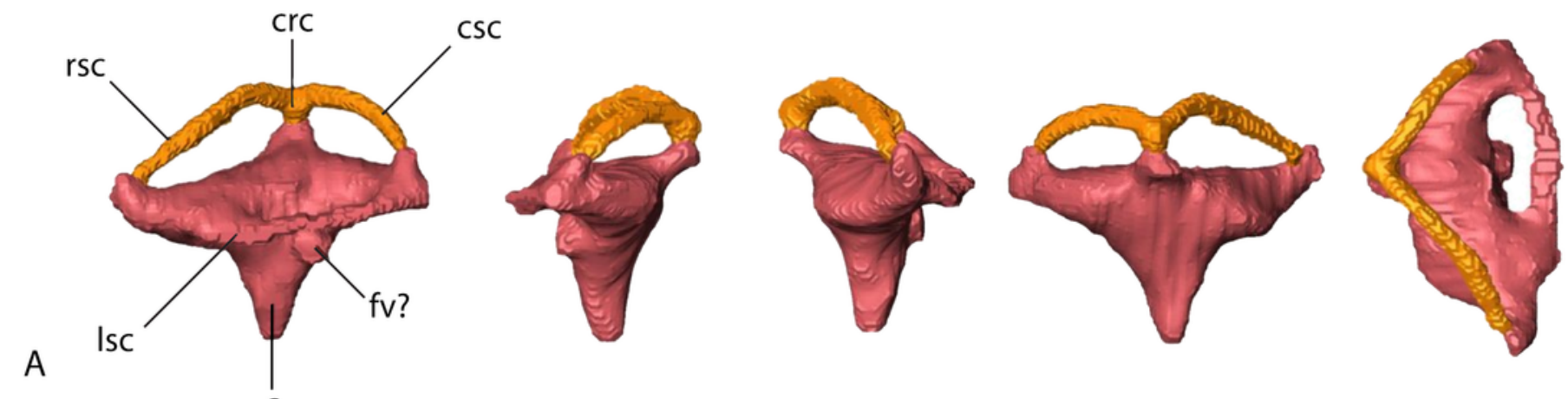

B
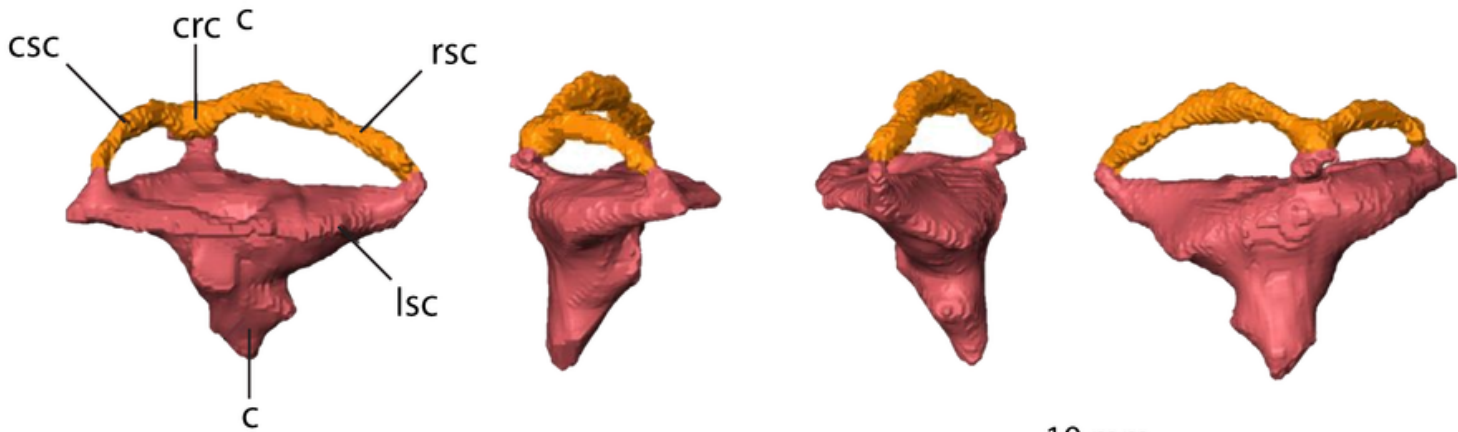

$10 \mathrm{~mm}$

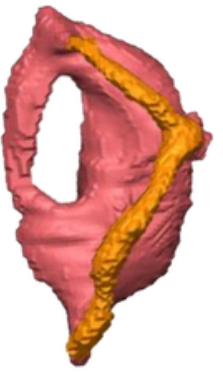

C
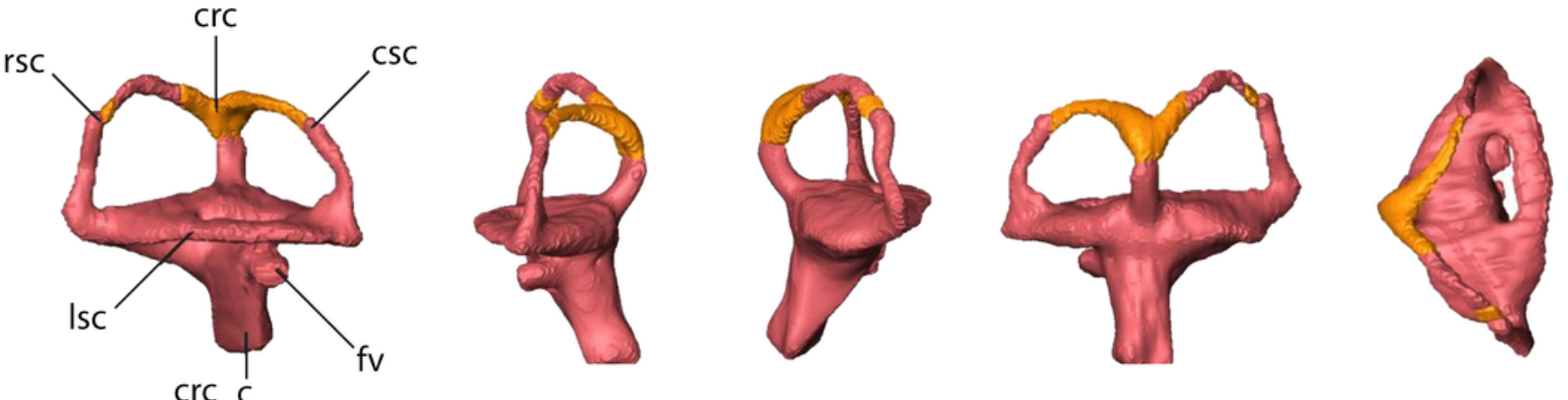

D
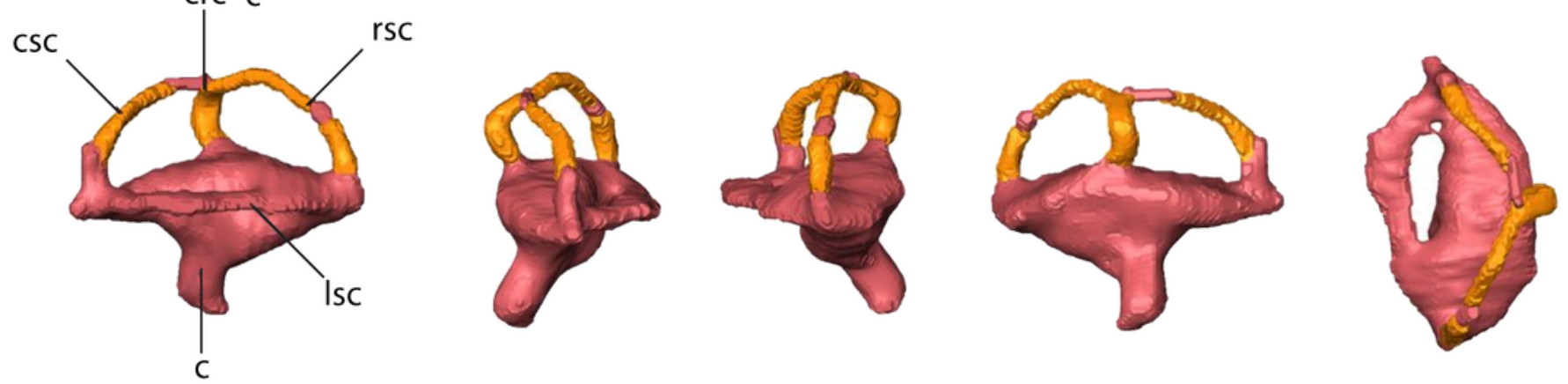


\section{Figure 7}

Endocranial anatomy of different phytosaurian taxa.

Comparisons based on existing endocasts and endocast reconstruction redrawn from Cope (1888), Case (1928), Mehl (1928), Camp (1930), Chatterjee (1978) and Holloway et al. (2013). Time-calibrated phylogeny based on Stocker and Butler (2013), Kammerer et al. (2016) and Ezcurra (2016). Endocasts of Parasuchus angustifrons and Ebrachosuchus neukami shown after retrodeformation. 


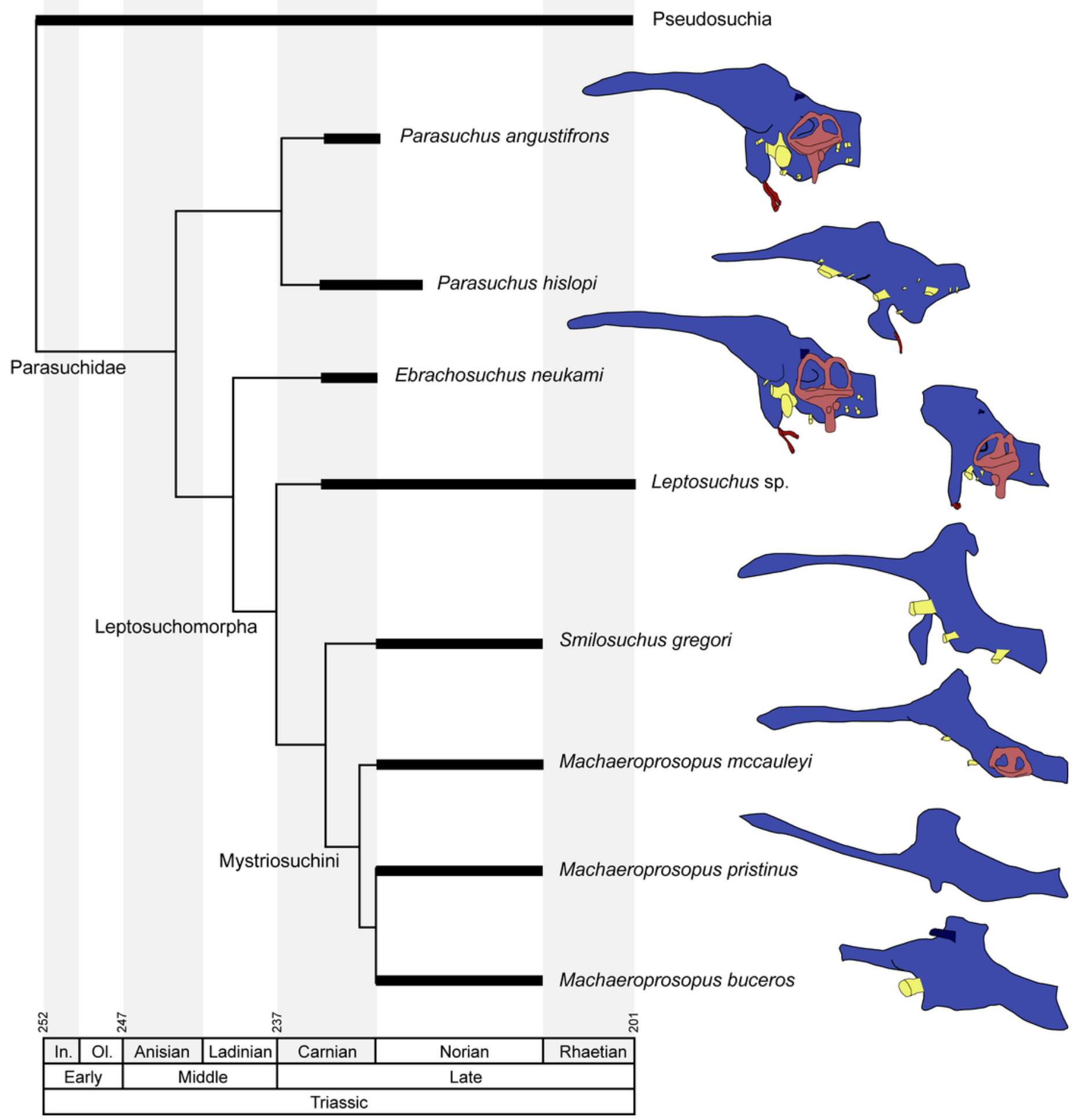


Figure 8

Retrodeformation of studied taxa.

(A) Complete and undistorted skull of Parasuchus hislopi (ISI R42) used as a guide for retrodeformation of (B) Parasuchus angustifrons (BSPG 1931 X 502) and (C) Ebrachosuchus neukami (BSPG 1931 X 501). Original (top) and retrodeformed (bottom) skull and respective endocasts shown for each taxon.

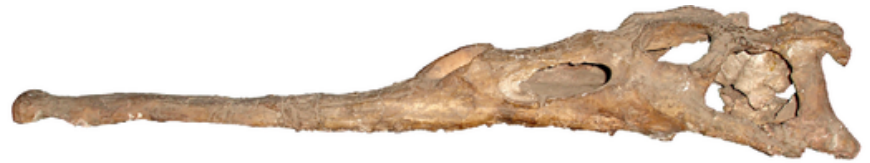

A

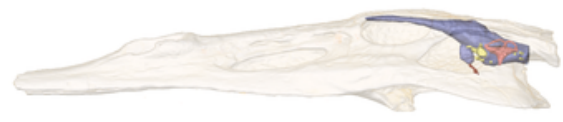

preserved

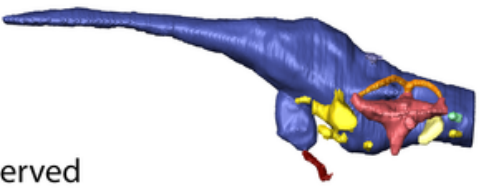

retrodeformation by dorsoventral scaling (factor ca. $40 \%$ )

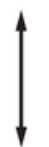

B
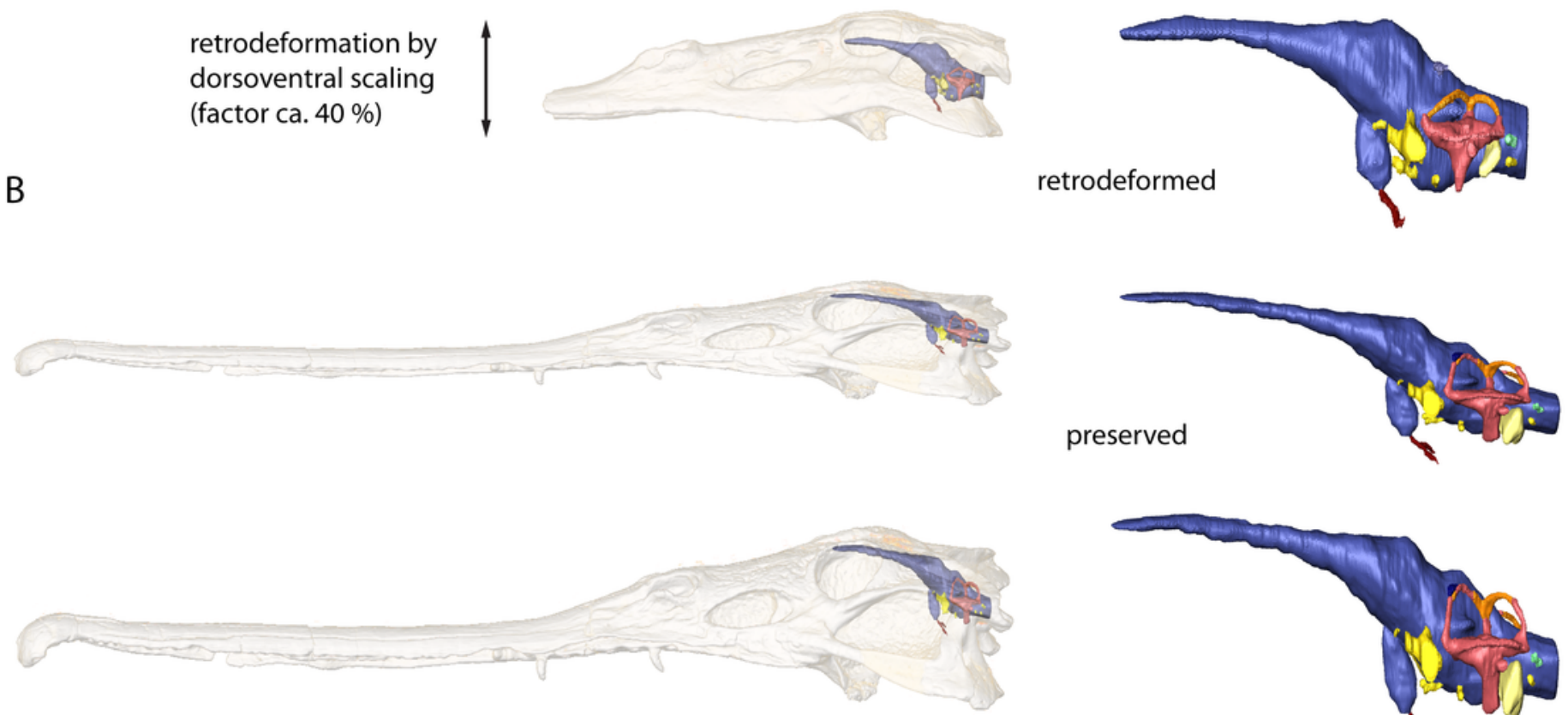

C

retrodeformed 